\title{
Funding orphan medicinal products beyond price: sustaining an ecosystem
}

\author{
Oriol de Sola-Morales ${ }^{1}$
}

Published online: 27 March 2019

○) Springer-Verlag GmbH Germany, part of Springer Nature 2019

Following a similar legislation in the USA [1], the EU passed a legislation in 1999 [2] to incentivize the development of an ecosystem around orphan medicinal products (OMP). In the last few years, there has been increasing debate about the strength of such incentives and whether the legislation needed to be reviewed to re-balance what is perceived to be an unfair situation.

Most of the debate has been fuelled by what is perceived to be an excessive cost per individual of OMP and the policy and political implications of funding these therapies in the advent of increasing personalized medicine, i.e., the ability to target therapies to small populations determined by a biomarker that can otherwise be considered orphan.

But certainly, there is more to it. We need to understand the many implications of the industry that is behind the development of OMP, and what are the economic, healthcare and social implications of such an industry, assuming obviously that the drug provides a sizeable benefit.

\section{First: despite the prices, society is willing to sustain funding for rare conditions}

It is basic economic theory that the prices of goods you provide in smaller quantities are higher. It is true that OMP drugs are more expensive than other drugs, but also that sales costs are statistically higher than for any other class of drugs. Prices can be misleading. Prices are an agreement between manufacturers and buyers, and somehow incorporate the willingness of both to remain on the market. It can well be that the prices of novelties subsidize old products or pipeline development, and that the prices in one country (USA) subsidize the lower prices in other countries (EU).

Oriol de Sola-Morales

osola@hittbcn.com

1 HiTT, Health Innovation Technology Transfer, Escoles Pies 40 Baixos, 08017 Barcelona, Spain
From a policy perspective, it is not the individual price that matters, but whether the overall budget impact is perceived as acceptable and that manufacturers have an acceptable profit.

There is also a bulk of literature estimating a limited budget impact of OMP in Europe. In 2011, Schey [3] predicted that an average expenditure for OMP in 2020 would be $4.6 \%$ of the total of drug expenditure, arguing that the level of increase would be tempered by the overall expansion of the drug market. The figure was confirmed in 2014 in a study from France and Sweden [4], and more recently Schlander et al. [5] who have estimated a maximum average expenditure in OMP of $16 €$ per annum per capita, roughly a $2.75 \%$ of the average annual per capita expenditure in that country for the year 2017 [6].

It has been accepted that OMP are not normal goods [7], but neither are they luxury goods that you can choose not to have. As a society, we do have an inclination to fund those most in need.

Why this happens is still a matter of debate, but it has been shown [8] that there is willingness to care for those more in need. Richardson and colleagues argue that there is a severity hypothesis, by which "a health service which increases a patient's utility by a fixed amount will be valued more highly when the initial health state is more severe" and also argue there is a caring effect, by which all individuals are willing to give a certain amount to those more in need, irrespective of the nature of the benefit, just because of a fairness idea that those more in need should also receive a share of the resources [9].

From the societal side, there is also good evidence showing that society is price sensitive regarding drug distribution, but also that there is a redistributing will. Several experiments show that at increasing costs, societies prefer to treat a larger group of patients, with the belief that more patients may get a fair share of their options when the benefit is spread amongst a larger group of individuals. There is also sufficient evidence to show that though society is willing to 
fund rare diseases more than per it's relative incidence, and that they are willing to do so as long as the 'common diseases' ere not underserved. Field data [10] suggest that the optimal distribution would be $20-30 \%$ of the drug expenditure going into uncommon diseases, but certainly that there is a floor level around $15 \%$ of the drug expenditure. Whilst these data have been confirmed across several countries and studies, with lay people and health-care professionals, we should understand that society is willing to devote a much larger proportion of funds to rare diseases just because they care [11].

The budget impact, at whatever the level, would be considered unfair if manufacturers made an excessive profit or benefited too much from a quasi-monopolistic position. Again, there are enough data to show this is not true, as OMP manufacturers make significant less profit than nonOMP dedicated companies. The paradox is that in fact, in the period 2011-2015, an analysis of the EBITDA of a sample of OMP dedicated companies showed negative figures $(-113 \%)$, compared to a positive trend from other pharmaceutical companies [12].

If manufacturers are continuously not making profits, they will leave the market. If they leave the market, we all lose as individuals and societies.

\section{Second: the lack of a mature ecosystem is a collective failure}

The Lisbon Treaty [13] compels all EU countries to move to a knowledge-based economy where investments in R\&D would be transferred to productive economy. On average, the EU has been spending a flat $2.04 \%$ of GDP in R\&D activities [14] (though the target was set at 3\%), where $23 \%$ is in the higher education sector (or $0.46 \%$ total GDP).

Huge efforts are being done by EU member states to fund Research in Universities, and fierce competition exists to achieve significant results, but most importantly to attract competitive and non-competitive funds to continue with the research programmes. It is within the aim of the treaty to point this research towards translational results; several grant programmes (most notably FP7 and Horizon 2020) have specific requirements to guide researchers to constitute companies and create a knowledge-based economy. Equal policies can be found at the national level, where the requirements of a broader impact are requested.

It turns out that the policies are being successful and part of it is now flourishing as cutting edge technology that can be applied to health care, even if the originating sector is not health itself; it has been made clear that "demographic and competitiveness challenges can be tackled, at least in part, by boosting innovation in healthcare" [15]. There has been some research [16] on the input and output ratios on health care, and it is roughly accepted that there is a threefold increase in the economic outputs of health. Equally, it has been proven [17] very difficult to track where these benefits go, as they may appear in several forms in the economy, maybe well distant from the health-care sector. In any case, there is a commitment to invest in health, as "investing in health also means investing in the health workforce" [18].

More than half of the compounds achieving an OMP designation are proposed by SME [19], which almost by definition are new companies emerging from scratch [20]. But we should not forget that of the many EMA-approved drugs, just $8.1 \%$ are marketed, meaning that the vast majority of the drugs will not make it to the patients regardless of the scientific, clinical and financial effort behind. It is however important to note that, though the OMP designation rate is high and shows a positive incentive, the rate of marketed drugs is relatively low, and limited to five to ten new drugs per year, which is proportionally lower than the non-OMP market. In that sense, it looks like despite a higher rate of approval, the marketing of such drugs is still insufficient, but that may be due not only to regulatory issues but also the lack of a clear commercialization strategy for these drugs to make it a sustainable endeavour.

From a financial point of view, the incentives are needed to allow these companies to bridge from the SME stage to the commercial stage. OMP-focused companies will not be able to compete in the drug market as SME. They do not have the financial capacity or the organisational structure to survive and will almost unanimously transit to either an IPO or a buyout by a larger company.

There have been some discussions on the causes [21] of the attrition rate, but one key message is that the OMP designation is not enough to grant success for patients or for entrepreneurs, as the survival rate of small SME companies cannot be granted to companies not having more than 2-year available cash. If transition from regulatory approval to economic sustainability cannot be granted, most of the R\&D effort will be lost, and only 'economically fit' companies will be able to survive.

A recent forecast on the OMP market shares shows that within the top 20 companies selling OMP, 8 or $40 \%$ would be small to mid-size biotechs with a limited portfolio, whereas most of the market share and revenues are captured by large manufacturers developing OMP as part of their portfolio. In the very recent past, we have seen two of these companies (namely, Shire and Celgene) being bought by larger companies, as part of their diversification strategy.

To our understanding, this shows the progressive maturity of the market, where small companies struggle to survive because of important R\&D expenditures, limited and costly sales and high financial costs (significantly higher than non-OMP focused), but creating enough appetite (incentives) for more to come to the arena and create a more 
competitive market. Should there not be the financial incentive of a buyout, most if not all of these companies would never get the financial support which allows them to survive during the transition period. The result of these companies not being sustainable or profitable means the collapse of the ecosystem, not only of the SMEs, but also of the surrounding industries that provide services and goods to these entrepreneurs.

The consequences for such failure are multifold: all the R\&D expenditure will be lost; a very powerful negative message would be sent to all those trying to create a knowledge society; large manufacturers with enough sales capacity to overcome the challenges of rare disease distribution may suffer from a shrinking innovative (and yes, more lucrative) pipeline; and most important, the market will never be complete, which means that there will be limited competition and prices will not be challenged. Strange as it may be, to have competition in an imperfect market (the demand is limited), we may have to allow some to make some extra profits, amongst other things to allow them to compensate the more mature markets. Some may argue that the margins from these companies are already too high, but a close scrutiny shows a cumulative annual EBITDA of $4.2 \%$, with profitability $(15 \%)$ well below the banking sector $(31 \%)$, transportation (19\%), beverage (21\%) and aligned with the software and hardware manufacturers [22].

\section{Third: OMP financing as a case of generational equity}

The traditional concept of vertical equity refers to redistribution of resources across population of different ages, normally from middle ages to both infants and the elderly. We may want to explore a generational equity, where this generation is asked to face new challenges and make important investments for the future generations, as previous generations did in the past.

Unfortunately, accessing true innovation is an everincreasing challenge. In recent decades, there have been massive investments in oncology, both from the manufacturers and the health-care systems, but the improvements are there and survival rates have significantly increased. We are continuously challenged by society to improve health care, but this will not be without investments, and these investments cannot be in old technology but in new or disruptive technologies.

Many may say the prices are simply unacceptable; here, I would suggest thinking about the consequences of not facing it: of course at a sustainable price and pace, but the societal costs new generations would face by the collapse of the biotech industry would be significantly higher.
Every generation has to face different challenges, and it is up to us to decide whether we are capable of facing it or not. Certainly the challenge is immense, but the economic and social consequences of the collapse of the biotech industry for the R\&D and the health-care sectors are also very significant. Future generations will have to overcome different, possibly greater challenges, but we have been lucky enough to see the transformation of health care towards a new dimension. Did the Romans think aqueducts were not sustainable, or do we think it did not pay-off sending a man to the moon?

Certainly, we need to make sure that future investments in health deliver the expected health benefits, and we need to make sure the price we pay for it is smaller than the societal benefit we get. Health gain is just one of the outputs of such investments, and we should be sure we pass on to new generations an ecosystem with at least as many opportunities as the one we inherited.

Funding OSM has consulted for many multinational pharmaceutical and device companies, as well as for several public governments and institutions.

\section{References}

1. The 97th United States Congress An Act to amend the Federal Food, Drug, and Cosmetic Act to facilitate the development of drugs for rare diseases and conditions, and for other purposes. Effective January 4 (1983)

2. European Parliament and Council Regulation (EC): No 141/2000 of 16 December 1999 on orphan medicinal products

3. Schey, C., Milanova, T., Hutchings, A.: Estimating the budget impact of orphan medicines in Europe: 2010-2020. Orphanet J. Rare Dis. 6, 62 (2011). https://doi.org/10.1186/1750-1172-6-62

4. Hutchings, A., Schey, C., Dutton, R., Achana, F., Antonov, K.: Estimating the budget impact of orphan drugs in Sweden and France 2013-2020. Orphanet J. Rare Dis. 9, 22 (2014). https:// doi.org/10.1186/1750-1172-9-22

5. Schlander, M., Dintsios, C.M., Gandjour, A.: Budgetary impact and cost drivers of drugs for rare and ultrarare diseases. Value Health 21(5), 525-531 (2018)

6. OECD: Pharmaceutical spending (indicator). https://doi. org/10.1787/998febf6-en. Accessed 16 Jan 2019 (2019)

7. Ford, J.: Drug prices comes under the microscope. Financial Times, 16 August 2015

8. Richardson, J., Iezzi, A., Maxwell, A.: How important is severity for the evaluation of health services: new evidence using the relative social willingness to pay instrument. Eur. J. Health Econ. 18(6), 671-683 (2016)

9. Richardson, J.: The wish to 'share' Health Economics Summer School. University of Heidelberg, Heidelberg (2016)

10. Desser, A.S.: Prioritizing treatment of rare diseases: a survey of preferences of Norwegian doctors. Soc. Sci. Med. 94, 56-62 (2013)

11. Richardson, J., Iezzi, A., Chen, G., Maxwell, A.: Communal sharing and the provision of low-volume high-cost health services: results of a survey. Pharmacoecon. Open. 1(1), 13-23 (2017) 
12. De Sola-Morales, O.: The success of EU OMP legislation: an empirical analysis. Value Health 20(9), A701 (2017)

13. European Union, Treaty of Lisbon Amending the Treaty on European Union and the Treaty Establishing the European Community, 13 December 2007, 2007/C 306/01

14. https://ec.europa.eu/eurostat/statistics-explained/index.php/ R_\%26_D_expenditure 16/1/19. Accessed 16 Jan 2019

15. EU_Investing in Health. https://ec.europa.eu/research/health/... innovation-in-healthcare-overview-report_en.pdf. Accessed 22 Feb 2019

16. Panel on the return on investments in health research. Making an impact. A preferred framework and indicators to measure returns on investment in health research. Ottawa, ON (Canada): Canadian Academy of Health Science (CAHS). http://www.cahs-acss.ca/e/ pdfs/ROI_FullReport.pdf (2009). Accessed 22 Feb 2019

17. Adam, P., Permanyer-Miralda, G., Guillamón, I., Berra, S., Pons, J.M.V.: Impact of clinical and health care services research on advancing knowledge. In: Study Applied to the CAHTA"s Research CALLS (3rd edn.) Catalan Agency for Health Technology Assessment and Research. Catalan Health Service. Department of Health. Government of Catalonia, Barcelona (2010)
18. EU INVESTING IN HEALTH Commission Staff Working Document Social Investment Package. http://ec.europa.eu/health/strat egy/docs/swd_investing_in_health.pdf (2013). Accessed 22 Feb 2019

19. Morel, T., Lhoir, A., Picavet, E., Mariz, S., Sepodes, B., Llinares, J.: Cassiman D Regulatory watch: the orphan drug pipeline in Europe. Nat. Rev. Drug Discov. 15(6), 376 (2016)

20. http://ec.europa.eu/growth/smes/business-friendly-environment/ sme-definition_en. Accessed 15 Jan 2017

21. Ernst \& Young Biotechnology Industry Report 2015: beyond borders Reaching new heights (2015)

22. Shaw, B.: We need to talk about pharma profits; Pharmaboardroom 2019. https://pharmaboardroom.com/articles/we-need-totalk-about-pharma-profits/

Publisher's Note Springer Nature remains neutral with regard to jurisdictional claims in published maps and institutional affiliations. 